F. R. Wightman of Wye College. The isolation of a new acid from coconut milk which gives about half the stimulation produced by whole milk was reported by L. H. Weinstein, L. G. Nickell and W. J. Tulecke (Boyce Thompson Institute and Chas. Pfizer).

New concepts on the relation between structure and auxin activity with special reference to the requirements for reactions with necessary binding sites were discussed in separate papers by Prof. K. V. Thimann and Dr. J. van Overbeek. Some physical chemical aspects of synthetic auxins with respect to their mode of action were presented by Prof. V. Freed (Oregon).

This was the first international conference in which the gibberellins were discussed. The Japanese scientists who carried out some of the early work with the gibberellins, T. Hayashi, J. Kato and Yusuke Sumiki, were on hand to present their most recent results. Dr. P. W. Brian (Imperial Chemical Industries, Welwyn), who was a pioneer in directing the attention of the Western world to the Japanese discoveries and who has been very active in this field, reported on new developments from bis lab. oratory. Evidence showing the probable widespread occurrence of gibberellin-like substances in higher plants was presented by C. A. West (University of California).

A feature of the Conference was a memorial dinner to the late P. W. Zimmerman (Boyce Thompson Institute), who with his associate A. E. Hitchcock first tested 2,4-D for its effect on plant growth and development. Other chemicals first tested in his laboratory include indolebutyric acid and 1-naphthaleneacetic acid as well as a variety of substituted derivatives of benzoic acid and various substituted aryloxyacetic acids. P. W. Zimmerman was originally a member of the organizing committee for this Conference but became ill while on a business trip and died in August 1958 at the age of seventy-four.

Financial support for the Conference was given by the Rockefeller Foundation, the National Science Foundation, and fifteen industrial companies interested in agricultural chemicals. George L. McNew, managing director of the Boyce Thompson Institute, was chairman of the Organizing Committee for the Conference. A. J. Vlitos was secretary of the Organizing Committee and chairman of the Programme Committee.
Lawrence P. Miller

\title{
THE BRITISH RAYON RESEARCH ASSOCIATION OPEN DAYS
}

$\mathrm{T}$ HE British Rayon Research Association held the fourth of its annual open days during May 6-8. The total attendance was $900-1,000$, a marked increase on the two previous years. Encouraged by the favourable reception last year, the senior chemist and senior physicist again gave short lectures, after lunch on each day, illustrating the relevance of the basic research to current problems in the textile industry. Instead of endeavouring to demonstrate all the work of the Association, a limited number of current researches on topical problems were illustrated rather more fully than usual, and it is believed that this approach may have been, in part at least, responsible for the very high attendance. Two aspects<smiles>O=C[C@H](O)[C@H](O)[C@H](O)[C@H](O)CO</smiles>

Cellulose
The recent work on the alkaline degradation of cellulose has considerably strengthened the conclusions on the mechanism put forward previously. This mechanism can be summarized in the following reaction sequence :

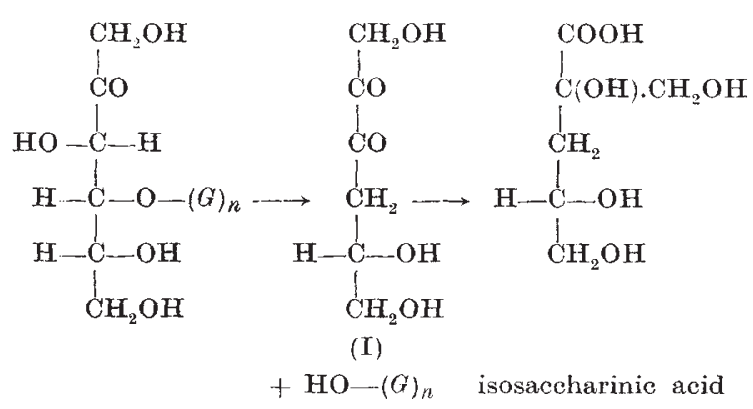

The intermediate (I) has now been isolated and its structure proved. The allkaline rearrangement of (I) is specifically catalysed by calcium and in lime water an almost theoretical yield of the isosaccharinic acid is obtained. The complex mixture of acids obtained with sodium hydroxide from this intermediate under the hot alkali-refining conditions used in purification of wood pulp is very similar, qualitatively and quantitatively, to that obtained from cellulose under the same conditions.

A considerable part of the resources of the Association are now directed to obtaining an understanding of the structure of textile fibres and attempting to correlate these with their physical, and particularly their mechanical, properties. On the chemical side a systematic study of the effect of known numbers of specific cross-links in cellulose and of substituents in specific regions, namely, crystalline or amorphous, of the cellulose on the mechanical properties has been 
in progress during the past year. The study of the formation of structure in solution-precipitated polymers is still in progress, but the first system examined, cellulose triacetate in chloroform, has been rejected. Polydecarnethylene terephthalate in benzophenone appears to be a more suitable system. Further work on the fine structure of cellulose has established that the microfibrillar structures observed in 'Tenasco' and 'Fortisan' materials sre not artefacts but are structural features of theso materials. Their significance with regard to the physical properties of these materials has not, however, been established.

The determination of the amount of crystalline material in any crystalline polymer requires special consideration for each case. In the case of the determination of crystallinity in cellulose by $\mathrm{X}$-ray methods the problem is to obtain the shape of the scattering of the amorphous component in which there is considorable orientation, as there is always considerable overlap with the crystalline reflexions. An independent assessment of the shape of the amorphous scattering curve is being made by comparing the information which can be extracted from the X-ray diagrams of highly oriented rayon fibres with the entirely 'amorphous scattering' of freezedried cellotetraose, and of ball-milled viscose and native cellulose fibres. (It is well established that ball milling will completely destroy the crystalline structure.) A study, by narrow-beam $\mathrm{X}$-ray and other techniques, of the nature of spherulites in nylon and of their offect on the mechanical properties of this material has been started.

It is difficult to find a new approach to understanding the mechanical behaviour of textile fibres.
A textile fibre is essentially a uniaxial solid and most measurements on stress/strain relations are referred to this axis. In many applications, for example the evaluation of the stress system in a yarn, the behaviour of the fibre in a direction perpendicular to this axis may be of equal importance. The mechanical behaviour of an elastic solid with axial symmetry should be completely characterized, within the region of small strains, by five constants. An attempt is being made to measure these constants on polymer films, which are more arnenable to such measurements than fibres, and to study their dependence on orientation.

The main emphasis in the Technological Department has been, and will continue to be, on quality. In continuous filament yarns, periodic over-straining caused by inadequate control of tension in winding processes can cause a variety of faults in cloth which often appear markedly only after dyoing. Instruments have been developed for measuring processing tensions and the properties of filament yams and these are now being markoted. This type of work has absorbed a large amount of technological effort. Certain weft-way types of cloth fault which occur as 'shiring' in continuous filament acetate fabrics and as 'cloudiness' in low construction nylon and 'Terylene' fabrics appear to be due to frictional effects between warp and weft yarns, and consequently, in the weaving research, more emphasis is being placed on these frictional effects.

The number of staff is 266 . This total is made up as follows: research staff, 90 ; laboratory and 1echnical assistants, 77 ; engineering, drawing office and maintenance staff, 59; library and administrative staff, 31 ; canteen staff, $9 . \quad$ L. A. WIsmmas

\section{NEW RESEARCH AND PRODUCTION FACILITIES OF CIBA (A.R.L.), LIMITED}

$\mathrm{N}^{\mathrm{n}}$ EW research laboratories, a new production plant and sales office extensions of Ciba (A.R.L.), Limited, at Duxford, Cambridge, were formally opened by Dr. R. Käppeli of Ciba, Limited, on May 21 during the celebration of the twenty-fifth anniversary of the establishment of the Company.

The new laboratories are housed in an L-shaped, two-storied building of concrete and brick construction with large plate-glass windows giving the maximum internal illumination in conformity with modern concepts in laboratory construction. The new building, together with the existing research blocks, encloses three sides of lawn and shrub garden. Internally, the uso of teak, exposed facing brick and white-painted surfaces accentuates the functional character of the design of the building.

The upper floor of the new building re-houses the rescarch and development department, and the swace thus vacated in the original buildings is being used for application and technical service work on wood adhesives. With the sdditional laboratory space now available in the upper floor of the new block, the group of graduate chemists and their technical assistants in the research and development department are able to explore more thoroughly the current resins marketed by the Company, resins of the epoxyresorcinol, phenol, urea and melamino types. The work is concerned with the development of resins and hardeners for casting and laminating purposes, for chip-board and wood-glue manufacture, as well as with specialized applications such as adhesives for metal bonding, printed circuits, high-temperature performance and a host of other uses. The extreme varioty of the applications to which these classes of resins may be put, and the differing conditions under which they are employed, necessitate a continued and intense search for modified and improved chemical properties and physical forms. An integral part of the investigations undertaken by this unit is the testing of these new and modified materials, and the upper floor of tho new building contains a test room well equipped with the necessary machines. This department maintains a close co-ordination with the other departments in the organization concerner with the application of existing products. There is, in addition, a lecture room where frequent colloquia and lectures are given by scientists from the plastics and relatod industries and by scientists from the academic world.

The ground floor of the new building contains the Iaboratories of the nowly formed fundamental research department, which is devoted to the study of the synthesis of new plastic substances with improved mechanical and olectrical properties and with hightemperature and chemical stability. The scope of the work is not restricted to adhesives, but embraces the 